\title{
The Respiratory Therapy Profession Is at a Crossroads
}

In 2007, the American Association for Respiratory Care (AARC) commissioned a task force to provide recommendations for the future direction of respiratory therapy in 2015 and beyond. ${ }^{1}$ After 3 years of study, conferences, and discussions with a wide range of individuals and organizations considered primary stakeholders in respiratory care and after defining the competencies needed by respiratory therapists in $2015,{ }^{2}$ the task force made 9 recommendations regarding changes needed to position the profession of respiratory therapy in 2015 and beyond for continued success. It is now more than 6 years since those recommendations were presented.

The third recommendation presented was that, by 2020 , all respiratory therapy educational programs award a baccalaureate or higher degree to all graduates. This recommendation was considered by the AARC Board of Directors in December 2012 but was rejected because of an insufficient number of baccalaureate programs (49 of a total of 433). Progress has been slow, but now 61 of 438 programs offer baccalaureate or graduate degrees. In the summer of 2015, the AARC Board of Directors established the goal that, by $2020,80 \%$ of respiratory therapists would have at least a baccalaureate degree or be in active pursuit of an advanced degree. ${ }^{3}$ On January 19, 2016, the AARC website called for all new respiratory care educational programs to award, at a minimum, a baccalaureate degree in respiratory care but did not mandate this change. ${ }^{4}$ However, the Commission on Accreditation for Respiratory Care (CoARC) has revised their policy so that as of January 1,2018 , it is mandated that all new respiratory care programs must award graduates of the program a baccalaureate or graduate degree upon completion of the program. ${ }^{5}$ Although we applaud the CoARC for stepping up to encourage the development of baccalaureate and graduate programs, this policy change does little to change

Dr Kacmarek has disclosed relationships with Orange Medical, Teleflex, Coviden, and Venner Medical. Dr Walsh has disclosed relationships with GE Healthcare, Vapotherm, Dräger Medical, and Maquet Getinge Group.

Correspondence: Robert M Kacmarek PhD RRT FAARC, Massachusetts General Hospital, 55 Fruit Street, Boston, MA 02114. E-mail: rkacmarek@partners.org.

DOI: $10.4187 /$ respcare. 05484 the pace of conversion of the currently accredited associate degree programs.

The recommendation to require a baccalaureate degree for entry level was the primary recommendation of the 2007 task force. A mandate rather than a recommendation

See the Original Study on Page 279

is necessary for this change to occur, since this was supported by the 37 stakeholder organizations attending the task force meetings and by surveys of directors of respiratory therapy educational programs ${ }^{6}$ and managers of respiratory therapy departments. ${ }^{7}$ However, in fairness, there was not unanimous support by respondents to these surveys in favor of a baccalaureate entry requirement to practice respiratory therapy, but the vast majority recognized the need for a baccalaureate degree for continued practice in the profession.

Under the leadership of past president Frank Salvatore in 2016, the AARC Board of Directors partnered with the Coalition for Baccalaureate and Graduate Respiratory Therapy Education and CoARC to identify the associate level respiratory care programs that would be easiest to convert to baccalaureate level. ${ }^{8}$ Once identified, contact was made, and assistance was offered to help facilitate a transition. In addition, a wonderful web-based tool was created by the AARC Executive Office to provide assistance. ${ }^{9}$

In this issue of RESPIRATORY CARE, additional support for the movement to a baccalaureate entry level is provided. Smith et $\mathrm{al}^{10}$ report the results of a survey of 2,170 respiratory therapists in the state of New York regarding the future of respiratory care. The primary finding from the 415 respondents was that the respiratory care profession is at risk of losing practitioners to other health-care fields. The reasons given for this attrition were limited manpower in their institutions, limited professional growth, and limited scope of clinical practice. In addition, the respondents cited salary levels and an inability to bill for services as reasons why individuals are leaving the profession. Most importantly, $60 \%$ of the respondents strongly agreed that the minimum academic standard for respiratory therapists should be a baccalaureate degree.

Smith et $\mathrm{al}^{10}$ go on to discuss their opinion that the Medicare Telehealth Parity Act will do a lot to expand the role of the respiratory therapist outside of acute care. They indicate that the Act includes respiratory therapists as qual- 
ified telehealth practitioners and adds respiratory therapists to the Medicare statutes allowing coverage for patient care services provided in remote settings. ${ }^{11}$ However, one must remember that respiratory therapists as a group are not considered professionals by the United States Department of Labor, since our entry level remains at the associate degree and does not meet the criterion of "prolonged course of specialized intellectual instruction." 12 Therefore, only those with a minimum of a baccalaureate entry level education are considered professionals and able to receive reimbursement for services provided. Nurses also do not have a baccalaureate degree as their minimal entry level education, but nursing negotiated an exception at the time the current labor laws were written. Unfortunately, respiratory therapy was not in existence in the 1930s when these laws went into effect. Thus, only those respiratory therapists with a baccalaureate degree will be eligible for reimbursement under the Medicare Telehealth Parity Act.

Respiratory therapist salary was a concern identified by Smith et al, ${ }^{10}$ and this is a concern of every respiratory therapist. In the health professions, the entry level academic credential and the ability to independently bill for services are directly related to salary. Physical therapy and pharmacy require a doctorate as their entry-level credential, speech and language pathology requires a master's degree, and social services and occupational therapy require baccalaureate degrees but are moving to master's degree entry-level requirements. Of note, all of these professionals receive higher salaries than respiratory therapists.

Respiratory therapists' lack of autonomy was a concern identified by Smith et al ${ }^{10}$ as well. It is clear to us that autonomy is explicitly linked to educational level. Many respiratory therapists with advanced degrees practice in roles (eg, highest clinical ladder, educators, clinical coordinators, researchers, informatics, public health, case managers, administrators) that are essential to the advancement of the profession. However, because a minimum of a baccalaureate degree is inconsistent, there is no solid foundation in which to clearly build these career pathways.

It is becoming increasing clear that if we expect respiratory care to continue to be a relevant and valued health profession, we must make some difficult decisions on future entry-level academic credentials. Wishing and encouraging all respiratory therapists to obtain a baccalaureate degree will not work. Consider the number of respiratory therapists with sufficient interest in their future to complete the New York State survey, only 415 out of 2,170 (22\%): This demonstrates that wishing and encouraging alone will not work. This response rate was similar to that of directors of respiratory therapy departments who completed the task force survey in $2010 .^{7}$ Surveys were sent to 2,368 managers of respiratory care departments who were members of the AARC, asking questions about the future of respiratory care in 2015 and beyond, and only 28\% responded. The professional apathy of many respiratory therapists has a profoundly negative effect on the continued development of the profession. We are clearly at a crossroads. Either we change radically and rapidly, or there is the real possibility that our profession will regress rather than progress. The status quo is not acceptable. The registered respiratory therapist academic requirements are essentially the same today as they were 40 years ago, whereas every health profession around us has changed!

From our personal knowledge of individuals practicing respiratory care throughout the world, we are the only group that does not require at least a baccalaureate degree as the minimum academic credential to enter practice. $\mathrm{Ca}$ nadian respiratory therapists have the baccalaureate degree as their minimum academic level to enter practice. Respiratory therapists or their equivalent trained in Saudi Arabia, Central and South America, Europe, and Asia all require a baccalaureate degree to enter practice.

We do not expect a mandate that by 2020 every respiratory therapy program provide a baccalaureate degree to all graduates, but we do ask for specific dates that mandate change; for example, that by 2020 , all programs have a viable plan to offer a baccalaureate degree and that, by 2027 (10 years from now), only respiratory therapy programs that offer a baccalaureate degrees or higher will remain accredited. Without specific pressure on the schools to change their curriculums, we are afraid there will be no movement to a baccalaureate degree minimum entry level into the profession. Very little change has occurred over the last 6 years, and we cannot see change occurring without a specific mandate, with deadlines set to achieve substantial change.

Combined, we have more than 70 years of respiratory therapist experience. We are very proud to be respiratory therapists and actively serve our profession and community. But we fear extinction of our profession. Time is of the essence. We are at a crossroads; change is occurring all around us, and the status quo is no longer acceptable. If you share our same concern, we encourage you to conduct a study similar to that of Smith et al ${ }^{10}$ or, better yet, act. If you have not completed your degree, please do so. In addition, contact your local AARC affiliate, educational programs, and licensure board to ask that they mandate higher educational standards for our patients and our profession.

Robert M Kacmarek PhD RRT FAARC Massachusetts General Hospital Harvard Medical School Boston, Massachusetts

Brian K Walsh PhD RRT-NPS FAARC American Association for Respiratory Care Irving, Texas

Harvard Medical School Boston Children's Hospital Boston, Massachusetts 


\section{EDITORIALS}

\section{REFERENCES}

1. Kacmarek RM, Durbin CG, Barnes TA, Kageler WV, Walton JR, O'Neil EH. Creating a vision for respiratory care in 2015 and beyond. Respir Care 2009;54(3):375-389.

2. Barnes TA, Gale DD, Kacmarek RM, Kageler WV. Competencies needed by graduate respiratory therapists in 2015 and beyond. Respir Care 2010;55(5):601-616.

3. American Association for Respiratory Care. AARC membership update: 2015 and beyond. 2016; http://www.aarc.org//app/uploads/ 2013/07/december_2012.pdf. Accessed December 30, 2016.

4. American Association for Respiratory Care. Position statement: respiratory therapist education. 2012; https://c.aarc.org/resources/position_statements/ documents/rt_education.pdf. Accessed January 13, 2017.

5. Commission on Accreditation for Respiratory Care. Proposed final revision to standard 1.01. 2016; http://www.coarc.com/29.html. Accessed December 30, 2016.

6. Barnes TA, Kacmarek RM, Durbin CG Jr. Survey of respiratory therapy education program directors in the United States. Respir Care 2011;56(12):1906-1915.
7. Kacmarek RM, Barnes TA, Durbin CG Jr. Survey of directors of respiratory therapy departments regarding the future education and credentialing of respiratory care students and staff. Respir Care 2012; 57(5):710-720.

8. Frank S. AARC BOD work, meeting and public meetings.

9. American Association for Respiratory Care. Transitioning for an associate degree program to a baccalaureate degree program. 2016; http://www.aarc.org/education/educator-resources/transitioningassociate-to-baccalaureate-degree-program/. Accessed December 30, 2016.

10. Smith SG, Endee, LM, Benz Scott L, Linden PL. The future of respiratory care: results of a New York State survey of respiratory care professionals. Respir Care 2017;62(3):279-287.

11. American Association for Respiratory Care. PACT day efforts promote telehealth bill. 2015; http://www.aarc.org/pact-day-effortspromote-telehealth-bill/. Accessed January 13, 2017.

12. United States Department of Labor. Wage and Hour Division (WHD) FLSA2006-26. 2006; https://www.dol.gov/whd/opinion/FLSA/2006/ 2006_07_24_26_FLSA.htm. Accessed January 13, 2017. 